\title{
Editorial: On Practices and Principles
}

\author{
Paul Griseri ${ }^{1}$
}

(C) Springer International Publishing AG 2015

We have departed from our normal policy for this issue - instead of selecting for our list of available papers a group that reflects some kind of thematic similarity, we have taken the next papers in line. This may give 14.3 a certain random feel in comparison with other issues, but is in line with policy and practices of many other journals. While the Executive Editorial team have always preferred to have some degree of unity between papers, it can become a little forced if taken as a fixed policy.

Still, this is not to say that the papers here have no connection. A line can be drawn connecting any two points, and a circle drawn around any three - it is more a matter of perceiving where the circle starts. Dominating this issue are the two jointed papers by Jane Anderson, the second of which is co-authored with Petia Sice and Carol Bennett. These relate to work they are doing using Socratic dialogue with client groups - one paper providing the conceptual background that they are using in their work, and the other a more direct report on how they go about the use of Socratic dialogue. It is an unusual type of content for this journal, which is more often concerned with theoretical foundations and underpinning concepts. But there has always been a strand of practice-based writing in Philosophy of Management, going right back to Volume 1, and we are keen to maintain this element. At times the editors have wondered whether we should divide the journal into distinct sections, one of which would be devoted to practice based material - any views from our readership on this question would be appreciated. In any case, Volume 15 is likely revert more to type, with one and possibly two Special Issues, as well as a more broadly based conference issue.

The paper by Jacob Bagha and Eugene Laczniak stands closer to the 'principle' end of the spectrum. They address the issue of the philosophical assumptions underlying neo-liberal economics, specifically discussing how ideas of Milton Friedman and Adam Smith can be all too easily over-simplified. Thus far the argument, if not well-worn, at least has its precedents. But they find a new twist in this debate, arguing that the conception of 'market' that is generally presumed to underpin the views of these writers is a prime source of the distortion, and that a broader conception of a healthy market as being, not simply efficient in operational terms, but also effective on social terms, is more suitable as a basis to construe the views of

Paul Griseri

p.griseri@mdx.ac.uk 
both of these writers. In arguing thus, they not only follow others in attempting to rehabilitate Smith, but also present Friedman in a more positive light than has been the case in many recent discussions.

Thematic in the Bagha-Laczniak paper is the role of rights, and this comes centre stage in Manuel Wörsdörfer's paper on the Equator principles and how these relate to different conceptions of CSR. Dr Wörsdörfer is critical of the role that the Equator Principles have played to date, and argues that a more positive, but also more assertive, conception of CSR is needed, one that requires organisations (and he specially discusses the 'Equator' banks) to play a more active role in what he dubs human rights due diligence, focusing culture change on the protection of human rights, engaging in advocacy rather than in simple corporate defence (which is what, in this editor's eyes, many CSR programme degenerate into). Banks are particularly important in this respect, given their central role in the economy, connecting real world of goods and services with the often stratospheric one of financial markets.

We also have two book reviews. Wim Vandekerckhove reviews Mike Metcalfe's text How Concepts Solve Management Problems in which the author presents a range of philosophically well-informed approaches to problem management - a text that that many postgraduate students might benefit from reading. In contrast we have Thomas Klikauer's more combative review of Joseph Heath's Morality, Competition and the Firm: the Market Failure Approach to Business Ethics which connects back to the understanding of markets as a key element in modern business ethics, a point of which the reviewer makes highly critical use.

Overall, these contributions are all, in their very different ways, concerned with the capacity for philosophical discussion to change business practice. More directly, the 'principles' based papers and the Heath review reflect the concern that philosophical discussion seems to be making slow progress towards making a tangible difference, to making business more humane. In contrast the Metcalfe text, and the Anderson-Sice-Bennett papers, point to methods that might be used to achieve change. Perhaps we need some accelerant, before we look back with regret at the lost years from 2008 up to the next world economic crisis. 